\title{
KINEMATICS OF USAIN BOLT'S MAXIMAL SPRINT VELOCITY
}

\author{
Milan Čoh ${ }^{1}$, Kim Hébert-Losier², Stanko Štuhec', Vesna Babić ${ }^{3}$, and Matej Supej ${ }^{1}$ \\ ${ }^{1}$ University of Ljubljana Faculty of Sport, Slovenia \\ ${ }^{2}$ University of Waikato, Faculty of Health, Sport, and Human Performance, \\ Adams Centre for High Performance, New Zealand \\ ${ }^{3}$ University of Zagreb, Faculty of Kinesiology, Croatia
}

Original scientific paper
https://doi.org/10.26582/k.50.2.10
UDC: $796.42: 577$

\begin{abstract}
:
This study investigated the maximal sprint velocity kinematics of the fastest $100 \mathrm{~m}$ sprinter Usain Bolt. Two high-speed video cameras recorded kinematics from 60- to 90-m marks during the men $100 \mathrm{~m}$ final at the IAAF World Challenge Zagreb 2011, Croatia. Despite a relatively slow reaction time (194 ms), Bolt won in $9.85 \mathrm{~s}$ (mean velocity: $10.15 \mathrm{~m} / \mathrm{s}$ ). His fastest $20-\mathrm{m}$ section velocity was $12.14 \mathrm{~m} / \mathrm{s}$, reached between $70-$ and $90-\mathrm{m}$ marks, by $2.70 \mathrm{~m}$ long strides and 4.36 strides/s frequency. At the maximal velocity, his contact and flight times were 86 and $145 \mathrm{~ms}$, respectively, and vertical ground reaction force generated equalled 4.2 times his body weight (3932 N). The braking and propulsion phase represented $37 \%$ and $63 \%$ of ground contact, respectively, with his centre of mass $(\mathrm{CoM})$ exhibiting minor reductions in horizontal velocity $(2.7 \%)$ and minimal vertical displacement $(4.9 \mathrm{~cm})$ emerged Bolt's maximal sprint velocity and international predominance from his coordinated motor abilities, power generation capacities, and effective technique. This study confirms that his maximal velocity was achieved by means of relatively long strides, minimal braking phase, high vertical ground reaction force, and minimal vertical displacement of CoM. This study is the first in-depth biomechanical analysis of Bolt's maximal sprinting velocity with the segmental reconstruction.
\end{abstract}

Key words: 100 m sprint, athletics, biomechanics, sport performance, sprint running

\section{Introduction}

Usain Bolt is one of the greatest athletes in the history of athletics. He is the winner of eight Olympic gold medals, as well as the world record holder in the $100 \mathrm{~m}(9.58 \mathrm{~s}), 200 \mathrm{~m}(19.19 \mathrm{~s})$, and $4 \mathrm{x}$ $100 \mathrm{~m}$ relay (36.84 s). During the $12^{\text {th }}$ International Association of Athletics Federations (IAAF) World Championships in Berlin in 2009, he established a new $100 \mathrm{~m}$ world record with a tailwind of $0.9 \mathrm{~m} / \mathrm{s}$, beating his previous world record by $0.11 \mathrm{~s}$ that had been set in 2008. Specifically, his 100 m world record was one of the most remarkable achievements in sprinting and was the largest improvement in the $100 \mathrm{~m}$ world record yet observed (Graubner \& Nixdorf, 2011). Recently, at the $15^{\text {th }}$ IAAF World Championships in Beijing, 2015, Bolt managed to maintain his world titles in the $100 \mathrm{~m}, 200 \mathrm{~m}$, and $4 \times 100 \mathrm{~m}$ relay despite participating in few competitions prior to the Championships due to injury.

Bolt's performance has been a subject of numerous media analyses, debates, and discussions, as well as biomechanical investigations. Research literature has attempted to explain Bolt's performance using spatio-temporal parameters (Graubner \& Nixdorf, 2011; Maćkała \& Mero, 2013), mathematical and biomechanical models (Beneke \& Taylor, 2010; Eriksen, Kristiansen, Langangen, \& Wehus, 2009; Graubner \& Nixdorf, 2011; Taylor \& Beneke, 2012), as well as anthropometrical characteristics (Charles \& Bejan, 2009; Maćkała \& Mero, 2013). There has also been attempts to estimate Bolt's $100 \mathrm{~m}$ sprinting potential (Barrow, 2012; Eriksen, et al., 2009), with a general consensus that he could have run below $9.5 \mathrm{~s}$ if only his reaction time had been better and under optimal environmental conditions (i.e., tailwind and high altitude), thus agreeing with the prediction by Denny (2008) that humans can run $100 \mathrm{~m}$ in $9.48 \mathrm{~s}$. However, kinematic data of Bolt running in competition are rare, and a more detailed investigation for Bolt's wholebody kinematics could assist in verifying some of the numerous theories of his sprinting success.

When Bolt set his current $9.58 \mathrm{~s}$ world record, his fastest $20-\mathrm{m}$ section time was $1.61 \mathrm{~s}$, reflecting 
a mean velocity of $12.42 \mathrm{~m} / \mathrm{s}$ (Graubner \& Nixdorf, $2011)^{1}$. This value is the highest absolute velocity ever reached by a sprinter during a $100 \mathrm{~m}$ race, and the fastest mean velocity $(10.60 \mathrm{~m} / \mathrm{s})$ over that race distance. Bolt's superior sprinting performance has been attributed to a strong acceleration phase, higher maximal velocity, advantageous power generation ability, and impressively long strides associated with his physical built (Beneke \& Taylor, 2010; Graubner \& Nixdorf, 2011).

Bolt participated in the IAAF World Challenge Zagreb 2011, Croatia. Our team of scientists had the opportunity to further study the fastest sprinter in the world. The specific aim was to investigate the kinematic parameters associated with Bolt's maximal sprint velocity during the men $100 \mathrm{~m}$ finals.

\section{Material and methods}

The IAAF World Challenge in Zagreb, Croatia, was held on September 13 $3^{\text {th }}, 2011$, at the Sports Park Mladost. Prior to this observational research project with a case study design, permission to record video footage of the men $100 \mathrm{~m}$ sprint final was granted by the Technical Delegate and Organizing Committee of the European Athletics Association. The temperature on the day of the competition reached $23^{\circ} \mathrm{C}$, and there was a head wind of $0.1 \mathrm{~m} / \mathrm{s}$ during the event (IAAF, 2011). The primary athlete of interest was Usain Bolt (age: 25 years, height: $1.96 \mathrm{~m}$, weight: $86 \mathrm{~kg}$; country: Jamaica). The other finalists were Kim Collins (35 years, Saint Kitts and Nevis), Richard Thompson (26 years, Trinidad and Tobago), Jaysuma Saidy Ndure (27 years, Norway), Mario Forsythe (25 years, Jamaica), Justin Gatlin (29 years, the United States), and Ivory Williams (26 years, the United States).

To record kinematic data from Bolt running, two high-speed digital cameras (EX-F1, Casio Computer Co., Ltd., Tokyo, Japan), sampling at 300 $\mathrm{Hz}$ with a pixel resolution of $720 \times 576$, were strategically placed along the track to capture data from the $100 \mathrm{~m}$ sprint. Prior to the race start, two reference frames (dimension: $2 \mathrm{~m}$ x $2 \mathrm{~m} \times 2 \mathrm{~m}$ ) were used to calibrate the final section (60 to $90 \mathrm{~m}$ ) of Bolt's lane. The calibration procedure considered eight points from the two reference frames. Furthermore, to accurately quantify the sprinting dynamics of all seven competitors, an additional high-speed camera was placed closer to the start of the race and video footage from the six official sports broadcasters televising the event were acquired. The official reaction and finishing times of all sprinters were acquired from the IAAF results of the IAAF World Challenge Zagreb 2011.
In a first instance, the videos from the sports broadcasters were used in conjunction with those from our cameras and the official race results to count the total number of strides taken and to compute the mean velocity, stride length, and stride frequency of each competitor. Bolt's data were compared to his fellow competitors and to his data available from previous races (Arribas, 2012; Hommel, 2009; Maćkała \& Mero, 2013). Secondly, the instance of Bolt's maximal sprint velocity reached was isolated $(\sim 85 \mathrm{~m})$ and relevant kinematic parameters were extracted over the fastest 20 -m section of his (70 to $90 \mathrm{~m}$ ). For data extraction, the computer program APAS (Ariel Performance Analysis System, Ariel Dynamics Inc., Coto de Caza Trabuco Canyon, USA) was used to reconstruct a 2D full-body biomechanical model using 16 reference points (Winter, 2005), which included the metatarsals; the ankle, knee, hip, shoulder, elbow, and wrist joints; and two head markers. The coordinate data from these 16 points were smoothed using a low-pass second-order Butterworth digital filter with a $14 \mathrm{~Hz}$ cut-off frequency and used to define 15 segments and the centre of mass (CoM) of the model according to standard anthropometric tables (Winter, 2005). Although the $300-\mathrm{Hz}$ data capturing frequency was used to determine flight and contact times, video digitization was performed at $100 \mathrm{~Hz}$ to reduce redundancy and manual labour. The joint position accuracy was estimated to $<2 \mathrm{~cm}$ in the sagittal plane based on the resolution of the system, measurement area, and typical manual digitization error.

The running stride (distance from foot strike to foot strike of the same foot) was divided into the ground contact (time of foot strike to toe off) and flight (time of toe off to foot strike) phases for both the left and right leg. The ground contact phase was further divided into the braking and propulsion phases according to the horizontal position of the $\mathrm{CoM}$ in reference to the ankle (braking: the CoM is in front of the ankle joint; propulsion: the CoM is behind the ankle joint), and included an instance of maximal amortization coinciding with the maximal knee flexion. From the digitized videos, the following kinematic parameters were extracted to describe Bolt's mechanics during his fastest $20-\mathrm{m}$ section: stride length; stride frequency; ground contact time; flight time; braking time; propulsion time; CoM height; CoM's horizontal and vertical velocities during braking, propulsion, and maximal amortization; horizontal displacement of the CoM during ground contact; distance between the foot and the vertical projection of the $\mathrm{CoM}$ at the ground contact; foot-CoM angle (angle formed using a line connecting the CoM to the metatarsal relative to the

\footnotetext{
In the same biomechanical analysis of the $12^{\text {th }}$ IAAF World Championships, Bolt's maximal velocity was reported to be 12.34 $\mathrm{m} / \mathrm{s}$, reached at the $67.90-\mathrm{m}$ mark of the race.
} 
ground) at the foot strike and toe off; foot-ground angle (angle formed using a line connecting the metatarsal to the ankle joint relative to the ground) at the foot strike and toe off; knee angle and angular velocity; foot horizontal velocity; and thigh angular velocity. Left- and right-leg values were extracted and side-to-side differences were investigated for key parameters. In addition, the maximal vertical force $\left(F_{\max }\right)$ was calculated according to a sine-wave model (Taylor \& Beneke, 2012) using the following equation:

$$
F_{\max }=m g * \frac{\pi}{2} *\left(\frac{t_{f}}{t_{c}}+1\right)
$$

where $m$ was Bolt's body mass $(\mathrm{kg}), g$ the gravitational acceleration $(9.81 \mathrm{~m} / \mathrm{s}), \mathrm{t}_{f}$ was the flight time (s) and $\mathrm{t}_{c}$ the ground contact time (s).

\section{Results}

\section{Bolt versus his competitors}

The race results and stride parameters of all the $100 \mathrm{~m}$ finalists are presented in Table 1. Despite having the slowest reaction time (194 ms), Bolt won the race in $9.85 \mathrm{~s}$, which was $0.16 \mathrm{~s}$ ahead of his closest competitor. Bolt had the least number of strides, slowest stride rate, and longest strides, which were equal to 1.25 times his body height.

\section{Bolt versus himself}

Bolt's $100 \mathrm{~m}$ sprint time at the World Challenge in Zagreb was $0.27,0.22$, and $0.16 \mathrm{~s}$ slower than his times at the 2009 Berlin World Championships, 2012 London Olympics, and 2008 Beijing Olympics, respectively (Table 2). In Zagreb, his reaction time, stride rate, and fastest $20-\mathrm{m}$ section were slower than those recorded in Beijing, Berlin, and London. His fastest 20-m section in Zagreb was also reached later in the race ( 70 to 90 versus 60 to $80 \mathrm{~m}$ ). In contrast, when setting his $9.58 \mathrm{~s}$ world record in Berlin, Bolt posted his quickest reaction time, took the least number of strides, and ran his fastest $20-\mathrm{m}$ section in comparison to the other three events herein presented. In Berlin, he reached his maximal velocity $\sim 20 \mathrm{~m}$ earlier than in Zagreb, reaching $99 \%$ of his maximal velocity at $48.18 \mathrm{~m}$ and his maximal velocity at $65 \mathrm{~m}$ (Hommel, 2009).

Table 1. Summary of race results and stride parameters of all the sprinters $(n=7)$ competing in the men $100 \mathrm{~m}$ finals at the IAAF World Challenge Zagreb 2011

\begin{tabular}{|c|c|c|c|c|c|c|}
\hline Athlete & Race time (s) & $\begin{array}{l}\text { Reaction } \\
\text { time (ms) }\end{array}$ & $\begin{array}{l}\text { Velocity }{ }^{a} \\
\text { (m/s) }\end{array}$ & $\begin{array}{l}\text { Stride count } \\
\text { (n) }\end{array}$ & $\begin{array}{c}\text { Stride } \\
\text { frequency }^{a} \\
(\mathrm{~Hz})\end{array}$ & $\begin{array}{c}\text { Stride } \\
\text { length }^{\mathrm{a}}(\mathrm{m})\end{array}$ \\
\hline Usain Bolt & 9.85 & 194 & 10.15 & 41.00 & 4.16 & 2.44 \\
\hline Kim Collins & 10.01 & 181 & 9.99 & 49.25 & 4.92 & 2.03 \\
\hline Richard Thompson & 10.03 & 177 & 9.97 & 44.50 & 4.44 & 2.25 \\
\hline Jaysuma Saidy Ndure & 10.13 & 167 & 9.87 & 43.25 & 4.27 & 2.31 \\
\hline Mario Forsythe & 10.16 & 188 & 9.84 & 46.50 & 4.58 & 2.15 \\
\hline Justin Gatlin & 10.17 & 177 & 9.83 & 43.25 & 4.25 & 2.31 \\
\hline Ivory Williams & 10.37 & 156 & 9.64 & 49.00 & 4.73 & 2.04 \\
\hline
\end{tabular}

Note: ${ }^{a}$ Values are means over the $100 \mathrm{~m}$ race.

Table 2. Summary of Usain Bolt's race results, stride parameters, and fastest 20-m sections during the men $100 \mathrm{~m}$ finals at the 2008 Beijing Olympic Games, 2009 Berlin World Championships, IAAF World Challenge Zagreb 2011, and 2012 London Olympic Games

\begin{tabular}{|c|c|c|c|c|c|c|c|c|}
\hline $\begin{array}{l}\text { Race } \\
\text { (year) }\end{array}$ & $\begin{array}{c}\text { Race time } \\
\text { (s) }\end{array}$ & $\begin{array}{l}\text { Reaction } \\
\text { time (ms) }\end{array}$ & $\begin{array}{l}\text { Velocitya } \\
\quad(\mathrm{m} / \mathrm{s})\end{array}$ & $\begin{array}{c}\text { Stride } \\
\text { count }(n)\end{array}$ & $\begin{array}{c}\text { Stride } \\
\text { frequency }^{a} \\
(\mathrm{~Hz})\end{array}$ & $\begin{array}{l}\text { Stride } \\
\text { lengtha }^{\text {lent }} \\
\text { (m) }\end{array}$ & $\begin{array}{l}\text { Fastest } \\
20-\mathrm{m} \\
\text { velocity } \\
(\mathrm{m} / \mathrm{s})\end{array}$ & $\begin{array}{l}\text { Fastest } \\
20-m \\
\text { section }\end{array}$ \\
\hline $\begin{array}{l}\text { Beijing OG } \\
(2008)^{c, d}\end{array}$ & 9.69 & 166 & 10.32 & 41.10 & 4.24 & 2.43 & 12.20 & $60-80$ \\
\hline Berlin WC (2009) ${ }^{\mathrm{e}}$ & 9.58 & 146 & 10.44 & 40.92 & 4.27 & 2.44 & 12.42 & $60-80$ \\
\hline $\begin{array}{l}\text { IAAF WoC } \\
(2011)^{\mathrm{c}, \mathrm{d}}\end{array}$ & 9.85 & 194 & 10.15 & 41.00 & 4.16 & 2.44 & 12.14 & $70-90$ \\
\hline $\begin{array}{l}\text { London OG } \\
(2012)^{c, d}\end{array}$ & 9.63 & 165 & 10.38 & 41.40 & 4.30 & 2.42 & 12.35 & $60-80$ \\
\hline
\end{tabular}

Note. ${ }^{a}$ Values are means over the $100 \mathrm{~m}$ race. ${ }^{b}$ Values are means over the fastest $20-\mathrm{m}$ section. Source: ${ }^{\mathrm{c}}$ Maćkała and Mero ${ }^{2}$ dArribas ${ }^{10}$; eHommel ${ }^{11}$. Abbreviations: OG - Olympic Games; WC - World Championships; IAAF WoC - IAAF World Challenge Zagreb 2011. 


\section{Bolt's fastest 20-m section}

Stride and kinematic parameters relating to Bolt's fastest $20-\mathrm{m}$ section $(70$ to $90 \mathrm{~m}$ ) are presented in Table 3. His fastest strides were, on average, $11 \%$ quicker and $5 \%$ longer than their corresponding means shown in Table 2, reaching 1.38 times his body height. Bolt's right-leg stride was $2.8 \%$ quicker and $1.5 \%$ shorter than his leftleg stride and was associated with a $10 \mathrm{~ms}(6.7 \%)$ shorter flight time, $5 \mathrm{~ms}(6.0 \%)$ longer contact time, $1.4 \mathrm{~cm}(34.1 \%)$ larger vertical displacement of the CoM, and $287 \mathrm{~N}(7.7 \%)$ smaller maximal $F_{\max }$.

Bolt's whole-body dynamics during his fastest 20-m section at the IAAF World Challenge Zagreb 2011 are illustrated in Figure 1, with key results summarized here. In the illustrated stride, the distance between the foot and the vertical projection of the CoM at foot strike was relatively small ( $34 \mathrm{~cm}$ or $17.4 \%$ of his body height). At the ground contact, the angle between the longitudinal axis of Bolt's foot and the ground was $19.5^{\circ}$, indicative of a plantar-flexed position. At the beginning of ground contact, the horizontal velocity of the CoM was $11.44 \mathrm{~m} / \mathrm{s}$. This velocity decreased to $11.13 \mathrm{~m} / \mathrm{s}(-2.8 \%$ from the initial contact) during the braking phase and reached $12.04 \mathrm{~m} / \mathrm{s}(+8.2 \%$ from braking) by the end of the propulsion phase. The lowest vertical CoM position occurred at the instance of maximal amortization (a maximal knee flexion), where the knee was bent to $\sim 145^{\circ}$. The range of vertical displacement of the CoM during Bolt's fastest stride was $4.9 \mathrm{~cm}$, the equivalent of $2.5 \%$ of his body height.

Graphical representations of linear velocities of the feet and angular velocities of the knees during Bolt's fastest 20 -m section are provided in Figures 2 and 3, respectively. During the ground contact phase, the mean horizontal velocity of the swinging

Table 3. Stride and kinematic parameters during Usain Bolt's fastest 20-m section of the $100 \mathrm{~m}$ finals at the IAAF World Challenge Zagreb 2011

$\left.\begin{array}{lccccccc}\hline \text { Stride } & \begin{array}{c}\text { Stride rate } \\ (\mathrm{Hz})\end{array} & \begin{array}{c}\text { Stride } \\ \text { length }(\mathrm{m})\end{array} & \begin{array}{c}\text { Flight time } \\ (\mathrm{ms})\end{array} & \begin{array}{c}\text { Contact } \\ \text { time }(\mathrm{ms})\end{array} & \begin{array}{c}\text { Braking } \\ \text { phase }(\%)\end{array} & \begin{array}{c}\text { Propulsion } \\ \text { phase }(\%)\end{array} & \begin{array}{c}\text { CoM vertical } \\ \text { displacement } \\ (\mathrm{cm})\end{array} \\ \hline \text { Right } & 4.42 & 2.68 & 140 & 88 & 35 & 65 & 5.5 \\ F_{\text {max }}(\mathrm{N})\end{array}\right)$

Note. ${ }^{a}$ Values are means for the right and left strides. Abbreviations: CoM - centre of mass; $F_{\text {max }}-$ maximal vertical force.

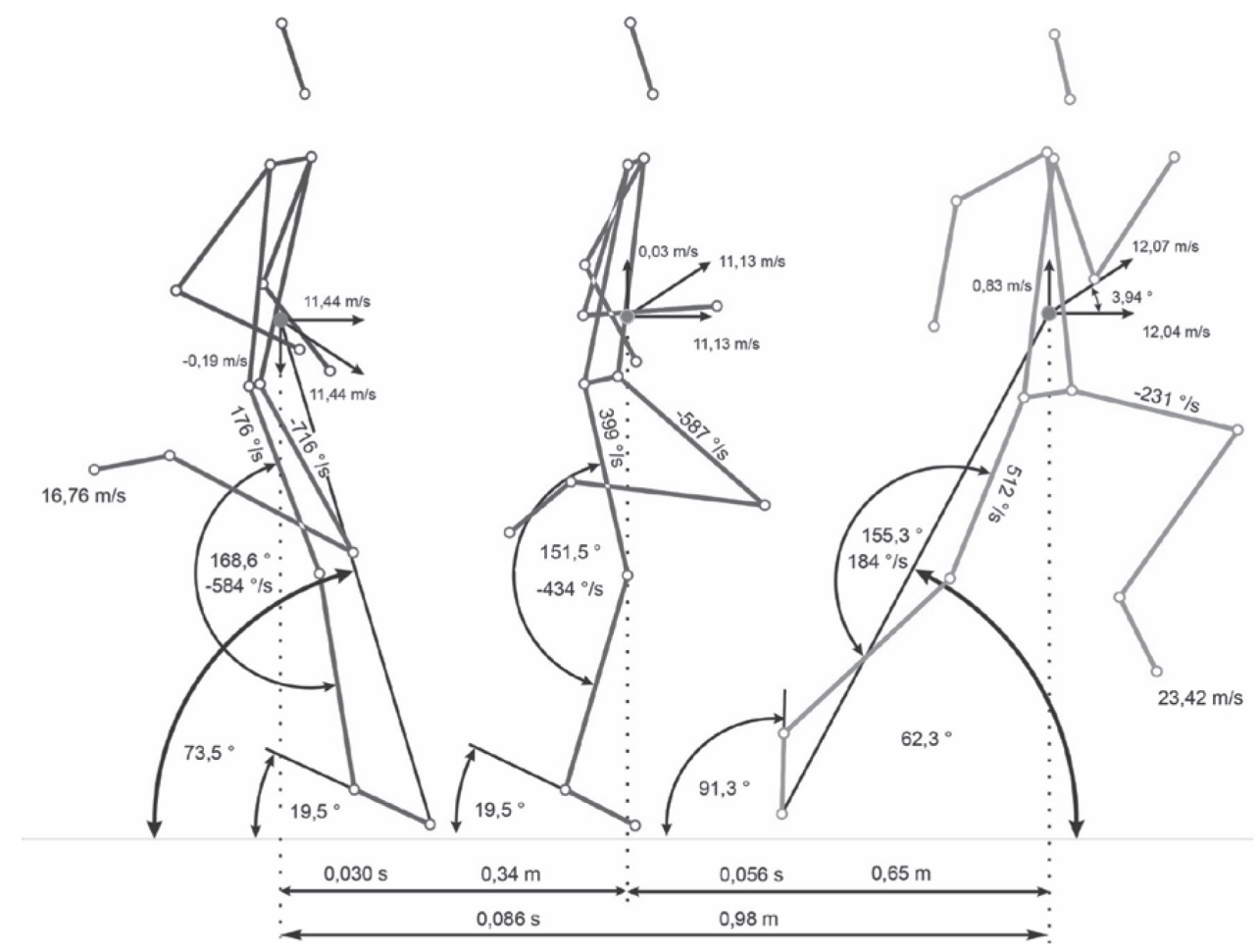

Figure 1. Representation of the whole-body dynamics during Usain Bolt's fastest 20-m section of the $100 \mathrm{~m}$ finals at the IAAF World Challenge Zagreb 2011. 
leg foot was $16.76 \mathrm{~m} / \mathrm{s}$ during braking and 23.42 $\mathrm{m} / \mathrm{s}$ during propulsion. The horizontal velocity of the swinging leg foot reached nearly twice that of the horizontal velocity of the CoM. Concurrently, high angular velocities at the knee of the swinging leg were observed, reaching $\sim 850 \%$ s towards the end of the contact phase (Figure 3).

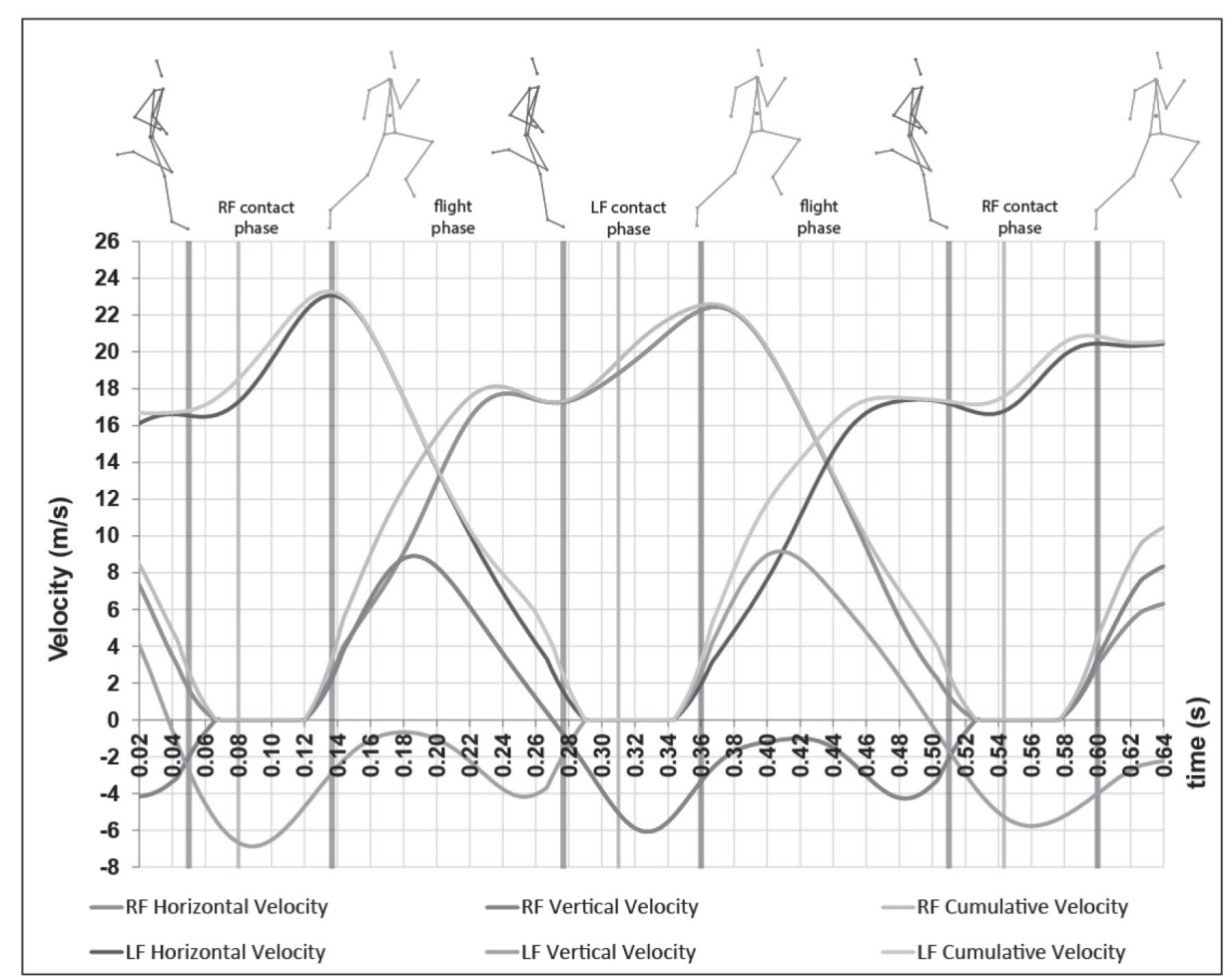

Figure 2. The linear velocities of the right $(R F)$ and left (LF) feet during Usain Bolt's fastest 20-m section of the $100 \mathrm{~m}$ finals at the IAAF World Challenge Zagreb 2011. The thicker bolded line separates the contact and flight phases, and the thinner bolded line separates the braking and propulsion phases.

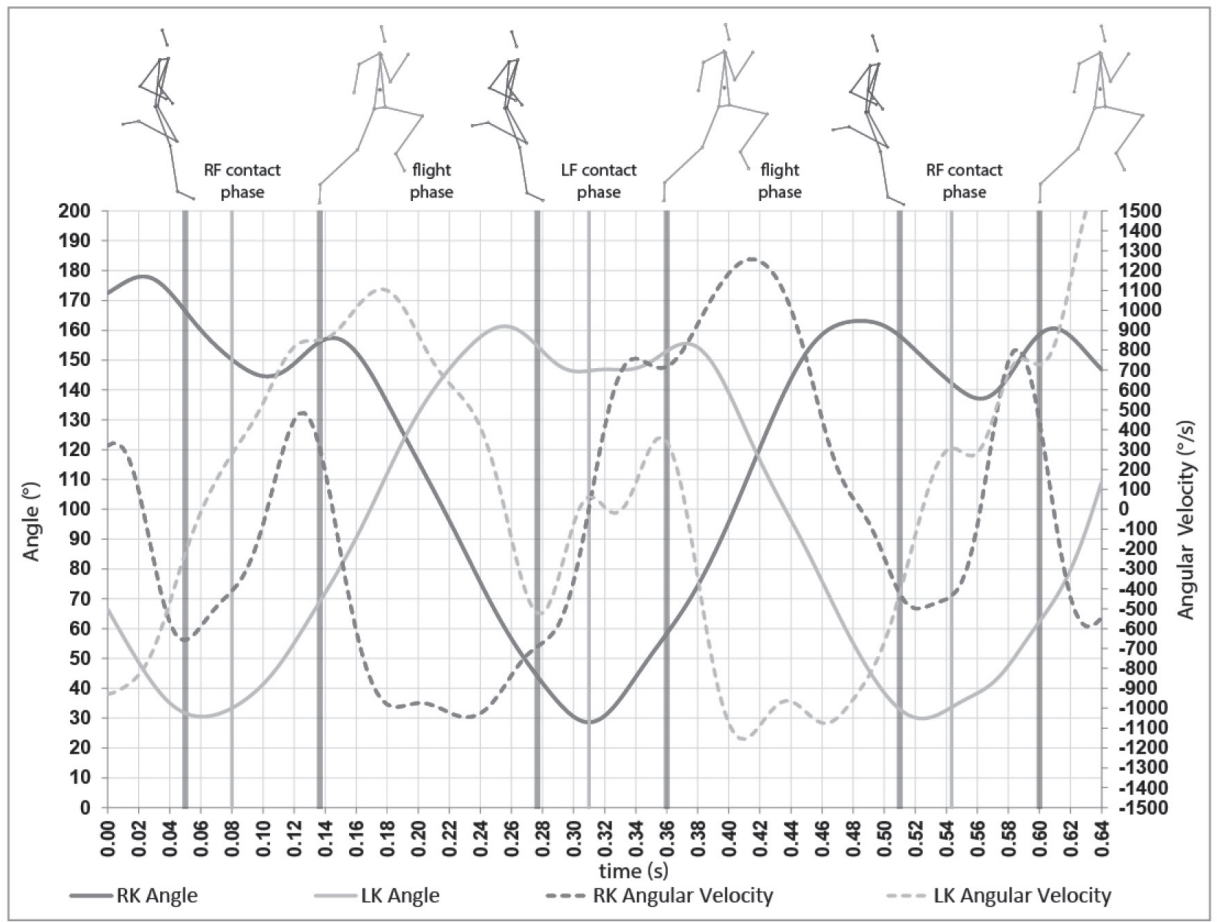

Figure 3. The angular displacements (where $180^{\circ}$ represents knee in full extension) and velocities (where positive values represent knee extension) of the right (RK) and left (LK) knees during Usain Bolt's fastest 20-m section of the $100 \mathrm{~m}$ finals at the IAAF World Challenge Zagreb 2011. The thicker bolded line separates the contact and flight phases, and the thinner bolded line separates the braking and propulsion phase. 


\section{Discussion and conclusion}

At the IAAF World Challenge Zagreb 2011, here investigated, Bolt won the $100 \mathrm{~m}$ finals in $9.85 \mathrm{~s}$ despite a rather slow reaction time. Compared to his competitors, Bolt took fewer and less frequent strides. However, these strides were on average $12 \%$ longer, which was a deterministic factor in his $1^{\text {st }}$ place finish. His fastest $20-\mathrm{m}$ section was run in $12.14 \mathrm{~m} / \mathrm{s}$ between $70 \mathrm{~m}$ to $90 \mathrm{~m}$, which was reached later in the race than his usual fastest 20 -m section, probably due to a slower start and initial acceleration phase.

Despite being $0.27 \mathrm{~s}$ slower compared to his world record, Bolt's performance in IAAF World Challenge Zagreb 2011 was nonetheless remarkable and would have won the gold medal for him that year at the Daegu World Championships where he was disqualified due to a false start. Scrutinizing his race performance using high-speed cameras and a methodological approach is worthwhile in comprehending his unparalleled sprint achievements. During his fastest $20-\mathrm{m}$ section in the analysed race, Bolt's mean flight and contact times were 145 and $86 \mathrm{~ms}$, respectively, with the braking and propulsion phases representing $37 \%$ and $63 \%$ of the ground contact. Kinetically, he developed a maximal vertical ground reaction force equal to 4.2 times his body weight $(3560 \mathrm{~N})$ and exhibited minor changes in the horizontal velocity $(0.31 \mathrm{~m} / \mathrm{s}, 2.7 \%)$ and vertical position $(4.9 \mathrm{~cm}, 2.5 \%$ body height) of his CoM, suggestive of an effective sprint running technique where displacement is oriented horizontally rather than vertically.

Sprint velocity is a product of stride length and frequency, where an increase in running velocity is demonstrated to result from an increase in both stride length and frequency up to $\sim 90 \%$ of maximal velocity beyond which further increments rely primarily on changes in frequency (Mero \& Komi, 1986). That said, the two parameters are interdependent, with their relationship being individual-specific (Donati, 1995) and mediated by several factors, including anthropometrics (Hunter, Marshall, \& McNair, 2004), sprinting mechanics (Hunter, et al., 2004; Mann \& Sprague, 1980), motor abilities (Maćkała, Fostiak, \& Kowalski, 2015; Mann \& Sprague, 1980), and the central nervous system (Gollhofer \& Kyröläinen, 1991; Mero, Komi, \& Gregor, 1992). While stride length depends on body height, leg length, and the ability of the leg extensors to generate high ground reaction forces (Hunter, et al., 2004; Maćkała, et al., 2015; Mero, et al., 1992), stride frequency further relies on the cortical and sub-cortical level of the central nervous system (Gollhofer \& Kyröläinen, 1991; Hunter, et al., 2004). Although it has been proposed that stride frequency plays a more deterministic role in the realization of maximal velocity than stride length and that the former discriminates between elite sprinters (Čoh, Milanović, \& Kampmiller, 2001; Donati, 1995; Lehmann \& Voss, 1997; Mero \& Komi, 1986), Bolt's physique obviously confers him a stride-length advantage in outperforming his competitors. When Bolt set the world record in the $100 \mathrm{~m}$ sprint, his mean stride frequency and stride length were $4.27 \mathrm{~Hz}$ and $2.44 \mathrm{~m}$, respectively (Hommel, 2009), whereas the corresponding mean values of the other seven finalists were $4.51 \mathrm{~Hz}$ and $2.23 \mathrm{~m}$, respectively. Bolt became the first athlete in the history of athletics to sprint $100 \mathrm{~m}$ in less than 41 strides. Again, Bolt's superior stride length distinguished him from his competitors. Throughout history, the $100 \mathrm{~m}$ sprint world record holders have become taller, heavier and leaner (Charles \& Bejan, 2009). Together with Bolt's stature (body height $=1.95 \mathrm{~m}$ ) and remarkable outcomes, these data are challenging the common belief that taller individuals are at a disadvantage when it comes to sprinting. The current study confirms that his maximal sprint velocity is achieved by relatively long strides rather than a high stride frequency, as well as by the minimal braking phase, high vertical ground reaction forces, and low vertical displacement of the CoM.

Contact time is the key parameter differentiating between elite sprinters (Čoh, et al., 2001). In the world-class athletes' sprinting, contact time is extremely short and lasts between 70 to $95 \mathrm{~ms}$ (Mann \& Sprague, 1980; Mero, et al., 1992; Taylor \& Beneke, 2012), during which time sprinters must develop high mass-specific ground reaction forces reported to range from $\sim 1.8$ to 4 times their body weight (Hunter, Marshall, \& McNair, 2005; Morin, Jeannin, Chevallier, \& Belli, 2006; Taylor \& Beneke, 2012). In our investigation, Bolt's maximal ground reaction force reached 4.2 times his body weight, which is clearly superior to all his fellow sprinters and at the top end of the spectrum. The forces we derived from the men $100 \mathrm{~m}$ final in IAAF World Challenge Zagreb 2011 are comparable to those previously reported for Bolt and exceeded those reported for other international-level sprinters (Morin, et al., 2006; Taylor $\&$ Beneke, 2012). Although the between-study differences might be in part due to different measurement methods (e.g., error associated with estimating ground reaction forces from kinematics rather than directly from force-measuring instruments), the data nonetheless illustrate Bolt's ability to develop high vertical ground reaction forces over a relatively short period of time. Beneke and Taylor (2010) suggest that Bolt generates greater mechanical power per muscle fibre than his fellow competitors. Our force estimates support their proposition that Bolt benefits from superior biomechanical efficiency and relative power generation compared to his fellow competitors. 
Although the contact and flight times provide vital information in terms of sprinting mechanics and performance, the ability to minimize the negative impacts of the braking phase and maximize the positive return from the propulsion phase is also noteworthy (Mero, et al., 1992). The shorter the braking phase, the smaller the reduction in the CoM horizontal velocity (Hunter, et al., 2004; Mann \& Sprague, 1980). At maximal velocity, the braking phase of elite male sprinters is reported to represent $\sim 43 \%$ of ground contact (Mero, et al., 1992). Herein, Bolt's braking phase represented only $37 \%$ of his ground contact, with the remaining $63 \%$ being utilized for propulsion. Bolt's horizontal CoM velocity during braking decreased by $2.8 \%$ only, and subsequently increased by $8.2 \%$ during propulsion, again supporting that Bolt is effective at minimizing the impacts during braking and maximizing the positive return during propulsion. Furthermore, as running velocity increases and contact time decreases, there is a reduction in the vertical displacement of the CoM in response to a need to increase horizontal force production (Brughelli, Cronin, \& Chaouachi, 2011). Bolt exhibited minor vertical CoM displacement $(4.9 \mathrm{~cm}$ or $2.5 \%$ of his body height) during his fastest $20-\mathrm{m}$ section in Zagreb. In elite athletes, vertical CoM displacement during maximal sprinting is reported to range from 4.7 to $12 \mathrm{~cm}$ (Hébert-Losier, Mourot, \& Holmberg, 2015; Mann \& Sprague, 1980; Mero, et al., 1992). The low vertical oscillation of the CoM observed here in Bolt highlights his high biomechanically efficiency and movement economy.

The position of the foot in relation to the vertical projection of the CoM at the foot strike influences the braking phase (Hunter, et al., 2005), with the general recommendation being to foot strike as close as possible to a point below the CoM (Brown \& Ferrigno). At his maximal velocity, the distance between Bolt's foot and vertical projection of his CoM at the ground contact was relatively small (34 cm or $17 \%$ of his body height), which was consistent with mechanics of sprinters running under $11 \mathrm{~s}$ on $100 \mathrm{~m}$ (Ito, Fukuda, \& Kijima, 2008). It is also generally recommended that sprinters strike the ground with the ankle in plantar-flexion to fully utilize the stretch-shortening cycle potential. An effective stretch-shortening cycle of the plantarflexors during the ground contact phase of running requires a pre-activation of the muscles (before the ground contact) prior to a rapid eccentric (stretch) phase at the ground contact immediately followed by a concentric (shortening) phase (Komi, 2000). Both the central and peripheral neural components are involved in optimizing the stretch-shortening cycle during running. In the current study, the angle formed by the longitudinal axis of the foot and the ground indicates plantar-flexion at the foot strike $\left(19.5^{\circ}\right.$, Figure 1), and is suggestive of the plantarflexors' pre-activation prior to the ground contact.

A high horizontal velocity of the swinging foot is important to preserve the horizontal velocity of the CoM during sprinting (Lehmann \& Voss, 1997). In IAAF World Challenge Zagreb 2011, $100 \mathrm{~m}$ race, the mean horizontal velocity of Bolt's swinging foot during the braking and propulsion phase was $16.76 \mathrm{~m} / \mathrm{s}$ and $23.42 \mathrm{~m} / \mathrm{s}$, respectively, with the latter being approximately twice the velocity of the CoM. The angular velocity of the thigh segment of the swinging leg ensures the horizontal velocity of the foot. Lehmann and Voss (1997) recorded maximal angular velocities of the swinging leg from 500 to $800 \%$ in sprinters running at least $10.50 \mathrm{~m} / \mathrm{s}$ and found positive correlations between the thigh's angular velocity and a sprinter's absolute velocity. In mid-stance, Bolt's angular velocity of the thigh was $587 \%$, which is at the lower end of the spectrum reported by Lehmann and Voss most likely due to his anthropometric characteristics, longer body segments, and slower stride frequency.

Compared to his $100 \mathrm{~m}$ sprint performances at the 2008 Beijing Olympics, 2009 Berlin World Championships, and 2012 London Olympics, Bolt's slower time in IAAF World Challenge Zagreb 2011 can be explained by several factors, such as the standard of competition (Hollings, Hopkins, \& Hume, 2012), environmental conditions (Hollings, et al., 2012; Linthorne, 1994), and sprinting mechanics (Hommel, 2009). For instance, Olympics and World Championships produce considerably faster $100 \mathrm{~m}$ times $(\sim 0.8 \%)$ compared to other competitions (Hollings, et al., 2012), all else being similar. Wind assistance up to the allowed IAAF limit of $2 \mathrm{~m} / \mathrm{s}$ for the record time recognition can improve $100 \mathrm{~m}$ times by $\sim 1 \mathrm{~ms}$ compared to the without-wind condition (Hollings, et al., 2012; Linthorne, 1994). During his world record $100 \mathrm{~m}$ performance in Berlin, Bolt's reaction time was quicker, stride count lower, maximal velocity faster and reached sooner in the race (Hommel, 2009), and wind conditions were slightly more favourable than in IAAF World Challenge Zagreb 2011, which could all contribute to explaining the $2.8 \%$ performance difference observed between these two races.

During Usain Bolt's fastest 20-m section at the IAAF World Challenge Zagreb 2011, 100 m finals, his performance was associated with a relatively long stride length, horizontal positioning of the foot close to the CoM at the ground contact, minimal braking phase, high vertical ground reaction forces, minimal vertical displacement of the CoM, as well as with high angular and horizontal velocities of his swinging leg. This study is the first in-depth biomechanical analysis with segmental reconstruction of Bolt's maximal sprinting velocity during an international competition. The results from this 
study can be used as a model for further developing specific aspects of maximal sprinting velocity in elite athletes and improve our understanding of Bolt's predominance in sprinting.

A more extensive analysis including all the sprinting phases (i.e., starting block, accelera- tion, speed-maintenance, and deceleration) can be suggested to fully comprehend Bolt's performance. For now, Bolt's predominance is suggested to be a resulting combination of anthropometrical characteristics, coordinated motor abilities, power generation capacities, and effective running technique.

\section{References}

Arribas, C. (2012). Con el rabillo del ojo a 45 por hora. [With the corner of the eye at 45 per hour. In Spanish.] El País. Retrieved August 6, 2012 from: http://deportes.elpais.com/deportes/2012/08/06/juegos_olimpicos/1344284896_730368. html

Barrow, J.D. (2012). How Usain Bolt can run faster - effortlessly. Significance, 9(2), 912. doi: 10.1111/j.17409713.2012.00552.x

Beneke, R., \& Taylor, M.J.D. (2010). What gives Bolt the edge - A.V. Hill knew it already! Journal of Biomechanics, 43(11), 2241-2243. doi: 10.1016/j.jbiomech.2010.04.011

Brown, L.E., \& Ferrigno, V. (2015). Training for speed, agility \& quickness ( ${ }^{\text {rd }}$ ed.). Champaign, IL: Human Kinetics.

Brughelli, M., Cronin, J., \& Chaouachi, A. (2011). Effects of running velocity on running kinetics and kinematics. Journal of Strength and Conditioning Research, 25(4), 933-939. doi: 10.1519/JSC.0b013e3181c64308

Charles, J.D., \& Bejan, A. (2009). The evolution of speed, size and shape in modern athletics. Journal of Experimental Biology, 212(15), 2419-2425. doi: 10.1242/jeb.031161

Čoh, M., Milanović, D., \& Kampmiller, T. (2001). Morphologic and kinematic characteristics of elite sprinters. Collegium Antropologicum, 25(2), 605-610.

Denny, M.W. (2008). Limits to running speed in dogs, horses and humans. Journal of Experimental Biology, 211(24), 3836-3849. doi: 10.1242/jeb.024968

Donati, A. (1995). The development of stride length and stride frequency in sprinting. New Studies in Athletics, 10(1), 51-66.

Eriksen, H.K., Kristiansen, J., Langangen, Ø., \& Wehus, I. (2009). How fast could Usain Bolt have run? A dynamical study. American Journal of Physics, 77(3), 224-228. doi: 10.1119/1.3033168

Gollhofer, A., \& Kyröläinen, H. (1991). Neuromuscular control of the human leg extensor muscles in jump exercises under various stretch-load conditions. International Journal of Sports Medicine, 12(1), 34-40.

Graubner, R., \& Nixdorf, E. (2011). Biomechanical analysis of the sprint and hurdles events at the 2009 IAAF World Championships in Athletics. New Studies in Athletics, 26(1/2), 19-53.

Hébert-Losier, K., Mourot, L., \& Holmberg, H.C. (2015). Elite and amateur orienteers' running biomechanics on three surfaces at three speeds. Medicine and Science in Sports and Exercise, 47(2), 381-389. doi: 10.1249/ mss.0000000000000413

Hollings, S.C., Hopkins, W.G., \& Hume, P.A. (2012). Environmental and venue-related factors affecting the performance of elite male track athletes. European Journal of Sport Science, 12(3), 201-206. doi: 10.1080/17461391.2011.552640

Hommel, H. (2009). Biomechanics report WC Berlin 2009 sprint men. Darmstadt, Germany. Retrieved November 19, 2014 from DLV Scientific Research Project: https://www.iaaf.org/about-iaaf/documents/research

Hunter, J.P., Marshall, R.N., \& McNair, P.J. (2004). Interaction of step length and step rate during sprint running. Medicine and Science in Sports and Exercise, 36(2), 261-271. doi: 10.1249/01.MSS.0000113664.15777.53

Hunter, J. P., Marshall, R.N., \& McNair, P.J. (2005). Relationships between ground reaction force impulse and kinematics of sprint-running acceleration. Journal of Applied Biomechanics, 21(1), 31-43.

International Association of Athletics Federations (IAAF). (2011). Results 100 metres men IAAF World Challenge Zagreb 2011. Retrieved November 19, 2014 from https://www.iaaf.org/results/iaaf-world-challenge-meetings/2011/iaafworld-challenge-zagreb-2011-4713/men/100-metres/race/summary

Ito, A., Fukuda, K., \& Kijima, K. (2008). Mid-phase movements of Tyson Gay and Asafa Powell in the 100 metres at the 2007 World Championships in Athletics. New Studies in Athletics, 23(2), 39-43.

Komi, P.V. (2000). Stretch-shortening cycle: A powerful model to study normal and fatigued muscle. Journal of Biomechanics, 33(10), 1197-1206.

Lehmann, F., \& Voss, G. (1997). Innovationen fuer den Sprint und Sprung: "ziehende” Gestaltung der Stützphasen Teil 1. Leistungssport, 6, 20-25.

Linthorne, N.P. (1994). Wind assistance in the 100m sprint. Track Technique, 127, 4049-4051.

Maćkała, K., Fostiak, M., \& Kowalski, K. (2015). Selected determinants of acceleration in the 100m sprint. Journal of Human Kinetics, 45, 135-148. doi: 10.1515/hukin-2015-0014 
Maćkała, K., \& Mero, A. (2013). A kinematics analysis of three best 100 m performances ever. Journal of Human Kinetics, 36, 149-160. doi: 10.2478/hukin-2013-0015

Mann, R., \& Sprague, P. (1980). A kinetic analysis of the ground leg during sprint running. Research Quarterly for Exercise and Sport, 51(2), 334-348. doi: 10.1080/02701367.1980.10605202

Mero, A., \& Komi, P.V. (1986). Force-, EMG-, and elasticity-velocity relationships at submaximal, maximal and supramaximal running speeds in sprinters. European Journal of Applied Physiology and Occupational Physiology, 55(5), 553-561. doi: 10.1007/bf00421652

Mero, A., Komi, P.V., \& Gregor, R.J. (1992). Biomechanics of sprint running. Sports Medicine, 13(6), 376-392. doi: 10.2165/00007256-199213060-00002

Morin, J.B., Jeannin, T., Chevallier, B., \& Belli, A. (2006). Spring-mass model characteristics during sprint running: Correlation with performance and fatigue-induced changes. International Journal of Sports Medicine, 27(2), 158-165. doi: 10.1055/s-2005-837569

Taylor, M.J.D., \& Beneke, R. (2012). Spring mass characteristics of the fastest men on Earth. International Journal of Sports Medicine, 33(8), 667-670. doi: 10.1055/s-0032-1306283

Winter, D.A. (2005). Biomechanics and motor control of human movement (3 ${ }^{\text {rd }}$ ed.). Hoboken, NJ: Wiley.

Submitted: September 6, 2017

Accepted: July 10, 2018

Published Online First: October 30, 2018

Correspondence to:

Prof. Milan Čoh, Ph.D.

University of Ljubljana, Faculty of Sport

Gortanova 22, 1000 Ljubljana, Slovenia

Phone: 041-729-356

Fax: +386 15207740

E-mail: milan.coh@fsp.uni-lj.si

\section{Acknowledgements}

The authors would like to thank members of the Organizing Committee of IAAF World Challenge Zagreb 2011 for facilitating this research project. This study was supported by the Slovenian Research Agency (ARRS).

\section{Disclosure statement}

The authors have no potential conflicts of interest to disclose. 